\title{
Functional outcome of vesicourethral anastomosis with bidirectional poliglecaprone vs. barbed polyglycaprone suture in robot-assisted radical prostatectomy
}

\section{Robotik radikal prostatektomide vezikoüretral anostomozda kullanılan iki yönlü dikenli sütür ve monofilaman poliglekapron sütür kullanımının fonksiyonel sonuçlara katkısı}

\author{
Mehmet Yıldizhan, Erem Asil \\ Ankara Şehir Hastanesi, Üroloji Kliniği, Ankara, Türkiye
}

Dergiye Ulaşma Tarihi: 16.06.2020 Dergiye Kabul Tarihi: 21.07.2020 Doi: 10.5505/aot.2020.72602

\begin{abstract}
ÖZET
GİRIŞ ve AMAÇ: Çalışmamız, prostat kanseri nedeniyle, robot yardımlı laparoskopik radikal prostatektomi (RYLRP) ameliyatı uygulanan hastaları, vezikoüretral anostomozda (VÜA), çift yönlü dikenli sütür ile monofilament poliglekapron sütürün sistografideki anastomoz ve ameliyat süresi, anostomoz kaçağı, üriner inkontinans, hastanede yatış ve kateterizasyon süreleri açısından değerlendirmeyi amaçlamıştır.

YÖNTEM ve GEREÇLER: 2017-2020 yılları arasında RYLRP ameliyatı yapılan 118 hastanın (40 çift yönlü dikenli sütür, 78 monofilament poliglekapron sütür) verileri restrospektif olarak analiz edildi. Hastaların demografik bilgileri, kateterizasyon süreleri, sistografi çekilme zamanları ve üriner inkontinans durumları hastane veritabanı kullanılarak elde edildi. Tüm cerrahi işlemler Da-Vinci Xi robotik cerrahi sistemleri (Intuitive surgical, Sunnyvale, CA) kullanılarak tek cerrah tarafından gerçekleş̧irildi. Hastalar kullanılan sütür tipine göre iki gruba ayrildı.

BULGULAR: Grup 1 deki 48 hastada $(\%$ 40,6) dikenli sütür ve Grup 2 deki 70 hastada $(\% 59,4)$ ise monofilament poliglekapron sütür kullanılmıştır. Gruplardaki ortanca yaş dağılımı, Psa seviyesi, ameliyat öncesi Uluslararası erektil fonksiyon indexi (international index of erectile function-IIEF) skorları, ortanca tahmini kan kaybı miktarı benzerdi. Grup 1 ve Grup 2 de ortalama anostomoz süresi 13(8-25) ve 21(12-31) (p<0.001), ortanca konsol süreleri sirasiyla 21(12-31), 110(73-205) ( $<<0.001)$ olarak gözlendi. Grup 1 ve Grup 2 deki hastalarda; ortanca sondalı olma süresi sirasıyla 7(7-14) güne 8(7-30) gün $(\mathrm{p}<0.001)$, ortanca hastanede kalma benzerdi $(\mathrm{p}=0,249)$, ameliyat sonrası 7 . günde çekilen sistogramdaki kaçak oranları sırasıyla $3(\% 6.3)$ 'a 15(\%21.4) olarak gözlendi. Grup 1 ve Grup 2 deki hastalarda kontinans oranları sırasılya; 1.ayda \%77.1 (n=37), $\% 75.7(\mathrm{n}=53)$; 3.ayda $\% 87.5(\mathrm{n}=42), \% 82.9(\mathrm{n}=58)$. Geç dönem postoperatif kontinans oranları dikenli sütür lehine anlamlı olacak şekilde yüksek iken $(\mathrm{p}=0,047)$, erken dönem kontinans oranları benzer bulunmuştur $(\mathrm{p}<0.001)$. Gruplarda bulunan hiçbir hastada mesane boynu kontraktürü izlenmedi.

TARTIŞMA ve SONUÇ: Robotik cerrahi erken kontinans sağlanmasını hızlandırsa da, en uygun sütür tipinin seçilmesi, kontinansın erken edinilmesi için halen klinik açıdan önemlidir. Mevcut çalışma, dikenli sütürün monofilament sütüre kıyasla daha kısa anostomoz süreleri ve erken sonda çıkartılmasını sağladığını kanitlamaktadir.
\end{abstract}

Anahtar Kelimeler: anostomoz, robotik cerrahi, prostat kanseri, sütür tipleri

\section{ABSTRACT}

INTRODUCTION: We aimed to evaluate anostomosis time, anostomosis leakage status, length of catheterization, urinary continence recovery following robot-assisted radical prostatectomy (RARP) using monofilament polyglecaprone suture vs. barbed suture during vesicourethral anastomosis.

METHODS: The data of 118 patients (40 bidirectional barbed sutures, 78 monofilament polyglycapron sutures) who underwent RARP between 2017-2020 were analyzed retrospectively. Demographic information, length of catheterization, cystography times and urinary incontinence status of the patients were obtained using the hospital database. All of the surgical procedures were performed by a single surgeon using Da-Vinci Xi robotic surgical systems (Intuitive surgery, Sunnyvale, CA). The patients were divided into two groups according to the type of sutures used.

RESULTS: Median age, Psa level, preoperative International index of erectile function (IIEF) scores, prostate biopsy gleason scores, length of hospital stay and median blood loss were similar in the groups. Median 
anastomosis time $13(8-25)$ and $21(12-31)$ ( $\mathrm{p}<0.001)$, median console times 21 (12-31), 110 (73-205) (p $<0.001)$ were observed in group 1 and group 2, respectively. In Group 1 and 2; median catheterization time was 7 (7-14) days to 8 (7-30) days ( $\mathrm{p}<0.001)$, and median hospitalization was similar $(\mathrm{p}=0.259)$. Leakage rates on the 7th postoperative day were observed as $15(21.4 \%)$ to $3(6.3 \%)$, respectively. The continence rates of the patients in Group 1 and Group 2; 77.1\% ( $\mathrm{n}=37), 75.7 \%(\mathrm{n}=53)$ at 1 st month; In the 3rd month, 87.5\% ( $\mathrm{n}=42)$, $82.9 \%(\mathrm{n}=58)$, respectively. While late postoperative continence rates were significantly higher in favor of barbed suture $(p=0.047)$, early continence rates were similar $(p<0.001)$. None of the patients showed bladder neck contracture in two groups.

DISCUSSION AND CONCLUSION: The current study proves that the barbed suture provides shorter anostomosis times and early catheter removal compared to the monofilament suture.

Keywords: anostomosis, robotic surgery, prostate cancer, suture type

\section{Giriş}

Prostat kanseri, dünya çapında, erkeklerde en sık görülen ikinci kanser olmakla birlikte ölüme neden olan kanserler arasında altınc1 sirada bulunmaktadir $(1,2)$. Günümüzde, lokal veya lokal ileri hastalık aşamalarında cerrahi (açık/laparoskopik/robotik radikal prostatektomi), radyoterapi veya ablasyon tedavileri hastalığı başarılı bir şekilde tedavi edebilmektedir. Cerrahiye uygun hastalarda en s1k kullanılan yöntem radikal prostatektomidir. Tekniğin Walsh ve arkadaşları tarafından ilk kez tanımlanmasından sonra, yaşam beklentisi 10 y1ldan fazla olan lokalize prostat kanserli hastalarda, radikal retropubik prostatektominin (RRP) etkinliği yıllar öncesinde kanıtlanmıştır $(3,4)$.

Günümüzde robot yardıml laparoskopik radikal prostatektomi (RYLRP) ürolojik alanda en fazla uygulanan robotik cerrahi uygulamadır. Dünyada, lokalize prostat kanserinin tedavisinde ilk cerrahi seçenek olarak uygulanmakta ve cerrahinin sonuçlarını iyileştirdiği kabul edilmektedir (5-9). Vezikoüretral anastomoz(VÜA) bu cerrahinin en kritik ve zaman alıcı adımıdır. İleri laparoskopi deneyimi gerektirir $(10,11)$. İlk başlarda, VÜA için daha çok vicryl sütürler kullanılıyorken laparoskopik ve robotik cerrahi uygulamaların artmasıyla kayma özelliği olan veya dügüm gerektirmeyen dikenli sütürleri kullanımına doğru bir eğilim ortaya çıkmış ve teknik olarak avantajlı olduğu çalışmalarla ortaya konulmuştur (12). Son zamanlarda yapılan çalışmalarda ise dikenli sütürün güvenilirlik ve postoperatif idrar kaçırma açısından geleneksel sütürlerle karşılaştırılabilir olduğu gösterilse de geleneksel monofilaman sütürlere kıyasla uzun süreli anastomoz iyileşmesi hakkında bir veri azlığı bulunmaktadır (13-16).

Adress for correspondence: Üniversiteler Mah. Bilkent Cad. No: 106800 Ankara - Türkiye e-mail: dr.mehmetyildizhan@gmail.com

Available at www.actaoncologicaturcica.com

Copyright $\mathbb{C}$ Ankara Onkoloji Hastanesi
Bu çalışmada, çift yönlü dikenli sütür ve poliglekapron sütür ile VÜA uygulanan hastalarımızı anastomoz, ameliyat ve ameliyat sonrası sondalı kalma süreleri, sistografide anastomoz kaçağı ve ameliyat sonrası idrar kaçırma durumları açısından değerlendirdik.

\section{Gereç ve Yöntem}

Etik kurul onayı alındıktan sonra (Ankara Şehir Hastanesi 1 no'lu Etik kurulu, onay no: E1-20-967 ) 2017-2020 y1llar1 arasinda RYLRP ameliyatı yapılan 118 hastanın (48 çift yönlü dikenli sütür, 70 poliglekapron sütür) verileri retrospektif olarak analiz edildi. Hastaların demografik bilgileri, kateterizasyon süreleri, sistografi çekilme zamanları ve idrar kaçırma durumları hastane veri tabanı kullanılarak elde edildi. Çalışmaya dahil edilen hiçbir hastanın geçirilmiş endoskopik/açık prostat cerrahisi veya pelvik radyasyon hikayesi yoktu. Hastaların idrar kaçırma durumlarına dair bilgiler ameliyat sonrası gerçekleştirilen poliklinik kontrollerindeki değerlendirmelerinden sağlandı. Çalışma 2013 yılında revize edilen Helsinki Deklarasyonuna hükümlerine uyularak gerçekleştirildi. Bütün hastalardan ameliyat öncesi yazılı onam alındı.

Tüm cerrahi işlemler Da-Vinci Xi robotik cerrahi sistemleri (Intuitive surgical, Sunnyvale, CA) kullanılarak tek cerrah (E.A.) tarafindan gerçekleştirildi. Hastalar kullanılan sütür tipine göre iki gruba ayrıldı. Grup 1 de bulunan hastalarda 3-0 dikenli sütür (VLoc ${ }^{180}$, Covidien Healthcare, MA, USA) kullanıld1. Grup 2 de bulunan hastalarda ise 2 adet 3-0 monofilaman poliglekapron (Monocryl ${ }^{\circledR}$, Ethicon, NJ, USA) sütürden 15 $\mathrm{cm}$ uzunlukta alınıp distal uçlardan düğüm atılarak iki yönlü hale getirildi. Gruplarda VÜA, daha önce Van Velthoven tarafindan tanımlanan teknikle gerçekleştirildi (13). Her bir grupta anastomoz tamamlandiktan sonra 
mesaneye $18 \mathrm{~F}$ foley kateter yerleştirilerek 150 mililitre serum fizyolojik ile doldurularak sızdırmazlık kontrolü yapıldı. Her hastaya ameliyat sonras $120 \mathrm{f}$ silikon drenaj kateteri yerleştirildi.

İlk değerlendirilen parametre anastomoz süreleriydi. Anastomoz süreleri ölçümünde her grupta, ilk sütür atılıp son düğüm tamamlanıncaya kadar olan süre esas alındı. Lenf nodu disseksiyonu yapılan hastalarda bu süreler toplam ameliyat sürelerinden çıkartıldı. Sonrasında gruplar sistografideki kaçak durumlarına, kateterli kalma sürelerine, kateter alındıktan sonraki 1. ay, 3. ay ve 6.aydaki kontinans durumlarına göre değerlendirildi. Sistografi bütün hastalara postoperatif 7. günde rutin olarak uygulandi. Sistografide kontrast madde kaçağı olmayan hastaların sondaları aynı gün alınırken, sistografide kaçağı olan hastalara 14 . ve/veya 21. günlerde çekilen sistogramdaki kaçak durumlarına göre karar verilerek sondaları çıkartıldı. İdrar kaçırma durumları günlük ped kullanımları esas alınarak değerlendirildi.

\section{Ístatistiksel analiz}

İstatistiksel analiz için windows için SPSS 22.0 (Chicago, IL, ABD) sürümü kullanıldı. Grupların tanımlayıcı istatistikleri hesapland. Sonuçlar ortanca(minimummaximum) olarak ifade edildi. Normal dağılıma uymayan veriler Mann-Whitney $U$ testi ile değerlendirildi. Buna ek olarak, Kategorik verilerin değerlendirilmesinde $\mathrm{Ki}$ kare ve Fisher Exact testleri kullanıldı. P değerinin 0,05 'in altında olması anlamlı kabul edildi.

\section{Sonuçlar}

Anastomozda kullanılan sütür tipine göre kategorize edilen hastaların temel klinik, patolojik ve preoperatif özellikleri Tablo 1'de özetlendi. Gruplardaki ortanca yaş dağılımı, Psa seviyesi, ameliyat öncesi uluslararas1 erektil fonksiyon indexi-5 (IIEF-5) skorları, ortanca tahmini kan kaybı miktarları benzerdi (Tablo 1).
Tablo 1 : Hastaların preoperatif parametreleri (Veriler ortanca(min-max) olarak sunuldu)

\begin{tabular}{|c|c|c|c|}
\hline Parametre & Grup 1 & Grup2 & p değeri \\
\hline Yaş (yıl) & $64(45-75)$ & $65(46-77)$ & 0,541 \\
\hline $\begin{array}{l}\text { Preoperatif } \\
\text { IIEF }\end{array}$ & $16(5-25)$ & $17(5-25)$ & 0,733 \\
\hline $\begin{array}{l}\text { Preoperatif } \\
\text { PSA (ng/ml) }\end{array}$ & $6,55(1-23)$ & $6,58(1-86)$ & 0,687 \\
\hline $\begin{array}{l}\text { Prostat } \\
\text { biyopsi } \\
\text { gleason skoru } \\
\text { (n) }\end{array}$ & & & 0,570 \\
\hline$\leq 6$ & 25 & 32 & \\
\hline $3+4$ & 13 & 20 & \\
\hline $4+3$ & 7 & 16 & \\
\hline$\geq 8$ & 3 & 2 & \\
\hline $\begin{array}{l}\text { Prostat } \\
\text { agırlığ } 1 \text { (gr) }\end{array}$ & $48.9(16-90)$ & $51,5(14-116)$ & 0,165 \\
\hline
\end{tabular}

Tablo 2: Hastaların intraoperatif ve postoperatif parametreleri (Veriler ortanca(min-max) olarak sunuldu)

\begin{tabular}{|c|c|c|c|}
\hline Parametre & Grup 1 & Grup2 & p değeri \\
\hline Anostomoz süresi (dk) & $13(8-25)$ & $21(12-31)$ & $<0.001$ \\
\hline Konsol süresi (dk) & $90(60-150)$ & $110(73-205)$ & 0.001 \\
\hline Kan kaybı miktarı(ml) & $100(50-300)$ & $100(10-400)$ & 0,908 \\
\hline Hastanede yatış süresi (gün) & $4(3-7)$ & $4(3-7)$ & 0.249 \\
\hline Sondalı olma süresi (gün) & $7(7-14)$ & $8(7-30)$ & $<0.001$ \\
\hline $\begin{array}{l}\text { Sistogramda idrar kaçağı } \\
(\mathrm{n}, \%)\end{array}$ & $3(\% 6.3)$ & $15(\% 21.4)$ & 0.024 \\
\hline \multicolumn{4}{|l|}{ Kontinan hasta oranı $(\mathrm{n}, \%)$} \\
\hline $\begin{array}{l}\text { 1. ayda } \\
\text { 3. ayda } \\
\text { 6. ayda }\end{array}$ & $\begin{array}{l}37(\% 77.1) \\
42(\% 87.5) \\
47(\% 97.9)\end{array}$ & $\begin{array}{l}53(\% 75.7) \\
58(\% 82.9) \\
61(\% 87.1)\end{array}$ & $\begin{array}{l}0,864 \\
0,491 \\
\mathbf{0 , 0 4 7}\end{array}$ \\
\hline $\begin{array}{lcc}\text { Cerrahi } & \text { sonrasi } & \text { gleason } \\
\text { skoru (n) } & & \\
& \leq 6 \\
& 3+4 \\
& 4+3 \\
& \geq 8\end{array}$ & $\begin{array}{l}31 \\
11 \\
3 \\
3\end{array}$ & $\begin{array}{c}34 \\
21 \\
9 \\
6\end{array}$ & 0,381 \\
\hline
\end{tabular}

Grup 1 ve 2 de ortalama anastomoz süreleri $13(8-25)$ ve $21(12-31) \mathrm{dk}(\mathrm{p}<0.001)$, ortanca konsol süreleri sirasiyla $90(60-150)$ ve $110(73-205) \mathrm{dk}(\mathrm{p}<0.001)$ olarak gözlendi. Grup 1 ve 2 deki hastalarda ortanca sondali olma süresi sirasiyla 7(7-14) ve8(7-30) gün olarak gözlendi $(\mathrm{p}<0.001)$. Ortanca hastanede kalma süresi her iki grupta benzerdi $(p=0,249)$. 
Ameliyattan sonraki 7. günde çekilen sistogramda kaçak oranları sırasıyla \%6.3(3) ve \%21.4(15) olarak gözlendi. Grup 1 ve 2 deki hastalarda kontinans oranları sirasiyla; 1.ayda \%77.1 $(\mathrm{n}=37), \% 75.7(\mathrm{n}=53)(\mathrm{p}=0,864)$; 3.ayda \%87.5 $(\mathrm{n}=42), \quad \% 82.9(\mathrm{n}=58)(\mathrm{p}=0,491)$ ve 6.ayda \%97.9(n=47), $\% 87.1(\mathrm{n}=61)(\mathrm{p}=0,047)$ olarak gözlendi (Tablo $2)$. Geç dönem postoperatif kontinans oranları dikenli sütür lehine istatistiksel olarak çok güçlü olmasa da anlamlı olacak şekilde yüksek iken erken dönem kontinans oranları benzer bulundu. Gruplarda bulunan hiçbir hastada mesane boynu kontraktürü izlenmedi. Ameliyat sonrasi 6 . ayda yapilan değerlendirmede IIEF-5 skorları her iki grupta benzer görüldü ( $\mathrm{p}=0.843$ )(Tablo2).

Ameliyat sonrası 7. günde çekilen sistogramda kaçak izlenen hastalara 7 gün aralıklarla sistogram tekrar çekildi. Dört hafta sonrasında halen anastomoz hattında kaçağ1 olan bir hastaya açık cerrahi yapılarak mesane boynu anastomozu yeniden yapıld.

\section{Tartışma}

Vezikoüretral anastomoz, radikal prostatektomideki en önemli adımı temsil eder. Anastomoz, idrar sizıntısını sinırlamak, morbiditeyi azaltmak ve erken kontinans1 sağlamak için su geçirmez, gerilimsiz bir şekilde ve emilebilir sütürlerle yapılmalıdır. Laparoskopik radikal prostatektominin ilk dönemlerinde anastomoz, açı cerrahiden edinilen deneyimlerle tek tek atılan sütürlerle uygulanmış ve ameliyatın en zorlu aşaması olarak tanımlanmıştır. Sonraki süreçlerde, Van Velthoven ve arkadaşları 2003 yılında tek düğümlü devamlı sütürasyon yöntemini tanımlamışlardır (17). Teknik monocryl sütür ile tanımlanmış olmasına rağmen sonraki süreçlerde dikenli sütürler ile anastomozun bu zorlu aşamasının kolaylaştırılması sağlanmıştır. Dikenli sütürlerin kullanımı ilk kez jinekolojik ve plastik cerrahi ameliyatlarında tanımlanmıştır $\quad(12,14)$. Sonrasında birçok kadavra ve hayvan çalışmaları gerçekleştirilerek konvansiyonel sütürler ile eşit biyouyumluluk ve gerilme direnci gösterdiği kanıtlanarak ürolojide de kullanılmaya başlanmıştır $(18,19)$.

Dikenli sütürün fiziksel özellikleri monofilaman poliglekapron sütürden farklıdır. İlk olarak, V-LocTM 180 biyomalzemesinin uzatılmış çözünme süresi Monocryl®'den

Adress for correspondence: Üniversiteler Mah. Bilkent Cad. No: 106800 Ankara - Türkiye e-mail: dr.mehmetyildizhan@gmail.com

Available at www.actaoncologicaturcica.com

Copyright $\odot$ Ankara Onkoloji Hastanesi (yarılanma ömrü 7-14 gün) daha uzundur (180 gün ve 90 gün) $(12,20-22)$. Yabanc1 cisim reaksiyonu nedeniyle oluşan inflamatuvar yanit, üretral sfinkter kompleksinin enflamasyonu ve gerilmesi nedeniyle dikenli grupta uzamış kontinans iyileşmesine neden olabilir. İkincisi, sütürün kopma mukavemeti (in vivo ortamda dikişin gerilme mukavemeti) V-LocTM 180 malzemesinde daha uzundur. Dokuzuncu ayda bile başlangıçta geriliminin $\% 65$ 'ini korumaktadır. Monocryl sütür ise 1 . haftada başlangıç geriliminin \%50-60'ını (boyalı olanlarda (\%60-70), 2. haftada ise gerilimin \%20-30'unu (boyalı olanlarda \%3040) korumaktadır. Dış üretral sfinkterin yakınında uzun bir süre devam eden sütür gerilim gücü, ameliyattan sonra dış sfinkter fonksiyonunu ve mesane boynunu tehlikeye atabilir (12,20-22). Haga ve arkadaşları RYLRP ameliyatından 9 ay sonra manyetik rezonans görüntüleme yaparak hastaları tekrar değerlendirdikleri çalışmalarında, dikenli sütür kullanımının grade 2 ve 3 üretral veya periüretral hasar oranını anlamlı şekilde arttırdığını göstermişlerdir. Her ne kadar ameliyattan sonraki erken dönemlerde daha fazla idrar kaçırma gözlense de ameliyattan 1, 9 ve 12 ay sonraki yaşam kalitesi değerlendirmeleri dikenli sütür lehine sonuçlanmıştır. (23).

Dikenli sütürlerin, kaymanın önlenmesi ve doku kuvvetinin farklı diken noktalarına dağılımı gibi avantajları vardır. Haliyle anastomozun gevşemesini önleyebilmekte ve anastomoz kaçağının önüne geçmektedir. Kaul ve arkadaşları, RYLRP yapılan ve VÜA'da dikenli sütür kullandıkları 51 hastalık çalışmalarında anastomoz sürelerinde $\% 27$ azalma olduğunu ve 1 . haftada anastomoz kaçağı veya uzun dönem mesane boynu striktürü olmadığını belirtmişlerdir (24). Williams ve arkadaşları ise dikenli sütürün Monocryl ${ }^{\circledR}$ 'e kıyasla daha travmatik olduğunu belirtmişlerdir. Sistogram sonuçlarına göre, kontrol grubu (Monocryl ${ }^{\circledR}$ ) ile randomizasyondan sonra dikenli sütür kolunda anastomozda kontrast kaçağ olduğunu bulmuşlar (\%20.0'a karş1 \%2.8; $\mathrm{p}=0.01)$, daha uzun kateterizasyon süresi (11.1 güne karş1 8.3 gün; $p=0.04$ ) ve daha fazla sütür maliyeti $(\mathrm{p}<0.001)$ bildirmişlerdir. Ancak çalışma sürecinde, aşırı gergin anastomoz yapmamak için tekniklerini değiștirdiklerini bildirmişler ve sonuç olarak, daha sonraki 
süreçlerde sistogramdaki kontrast kaçağ 1 insidansının dikenli grupta \%6.3'e düştüğünü belirtmişlerdir (25). Anastomoz yaparken anastomozun kaçırmaması için sütürlerin daha gergin bir şekilde oturmasını sağlamak cerrahi esnasında cerrahın daha iyi hissetmesini sağlasa da uzun dönem sonuçlar beklendiği gibi olmayabilir. $\mathrm{Bu}$ nedenle seçilen sütür materyalinden bağımsız olarak üretra ve mesane boynunun bir araya gelmesini sağlayan optimal bir gerginlik başarılı bir anastomoz için en güvenilir yöntemdir. Bizim çalışmamızda da 7. günde çekilen sistogram sonuçları esas alındığında erken dönem anastomoz kaçağı oranları dikenli sütür grubu lehine istatistiksel olarak anlamlı olacak şekilde düşük izlendi.

Sammon ve arkadaşları, VÜA'da dikenli sütür $(\mathrm{n}=31)$ ve monofilaman poliglekapron sütür $(n=33)$ kullanarak RYLRP yaptıkları hastaları değerlendirdikleri randomize kontrollü çalışmalarında yan etki görülmeden VÜA süresinde, dikenli sütür kullanılan grupta \%26 oranında azalma izlenmiş, hiçbir hastada idrar yapamama ve yan etki sıklığında artış görülmemiştir. Ameliyattan 6 hafta sonra yapilan değerlendirmede diğer üriner fonksiyonlar açısından fark izlenmemiştir (13). Massoud ve grubunun yaptığı çalışmanın sonuçları da, anastomoz süresi ve tekniğinin uygulanabilirliği açısından dikenli sütür kolunu desteklemektedir. V-Loc kolunda kontrol grubuna kıyasla anlamlı olmayan uzun bir iyileşme süresi izlenmiştir (26).

Monocryl gibi oldukça kaygan sütürlerle VÜA yapmaya çalışmak oldukça zorlayıc1 olabilmektedir ve belli bir deneyim gerektirmektedir. Ancak V-Loc sütürlerle yapılan anastomozlar üzerlerindeki dikenler nedeniyle bir kez oturtulduktan sonra daha az oranda gevşediği için anastomoz kısa sürmekte ve nihayetinde ameliyat sürelerinin kısalmasını sağlanmaktadır. Tewarinin, dikenli $(n=50)$ ve polyglactine $\quad(\mathrm{n}=50)$ sütür kullanarak gerçekleştirdiği çalışmada RYLRP'de anlamlı bir şekilde dikenli sütür lehine anastomoz sürelerinin daha kısa olduğu ve klinik olarak anlamlı idrar kaçırma veya idrar yapamama durumunun görülmediğini belirtmişlerdir (27). Bizim çalışmamızda da literatürü destekleyecek şekilde V-Loc kullanımının anastomoz süresini kısalttığ tespit edildi.
Retrospektif bir çalıșmada, Polland ve grubu V-LocTM 180 sütürünü standart 3.0 monofilaman sütür ile karşılaştırmış ve 6 . haftada (sirasiyla $\% 52$ ve $\% 48$ ) ve 6 . ayda (\%88 ve \%84) çalışma ve kontrol grupları arasında kontinans açısından fark görülmediğini belirtmiştir. Anastomoz sürelerinin daha kısa olduğunu ve klinik olarak idrar kaçırma veya idrar yapamama durumunun görülmediğini belirtmişlerdir (28). Hemal ve arkadaşları aynı tip sütürleri karşılaştıran 50 hastanın prospektif bir pilot çalışmasını gerçekleştirmiş ve dikenli sütürün ameliyat sırasında güvenli ve etkili olduğunu bildirmişlerdir. Ameliyattan hemen sonraki dönemde hiçbir hastada semptomatik idrar kaçağı, idrar yapamama veya anastomoz darlığ1 görülmemiştir (29). Bizim çalışmamızda ameliyat sonrası 7.günde yapılan sistogram değerlendirmelerinde monocryl kolunda daha fazla anastomoz kaçağı gözlendi. Ayrıca,1.ay ve 3.ayda hastaların idrar kaçırma durumları arasında fark gözlenmezken 6.ayda yapılan değerlendirmede kontinans V-Loc lehine anlamlı görüldü.

Manganiello ve arkadaşları ise RYLRP yapılan 70 hastalık çalışmalarında (ilk 35 hastada dikenli sütür grubu ve sonraki 35 hastada monofilaman poliglekapron kullanılmış) 5. aydaki kontrollerde mesane boynu daralması izlenmemiş ve idrar kaçırma oranları benzer bulmuştur (30). Bizim çalışmamızda da hastaların hiçbirinde mesane boynu darlığı gözlenmedi.

Çalışmamızın çeşitli limitasyonları bulunmaktadır. Öncelikle çalışmamız retrospektif olarak gerçekleştirilmiştir. İkincisi, 6 aylık erken dönem sayılabilecek takip sürelerine sahiptir

Robotik cerrahi erken kontinans sağlanmasını hızlandırsa da, en uygun sütür tipinin seçilmesi, kontinansın erken edinilmesi için halen klinik açıdan önemlidir. Mevcut çalışma, dikenli sütürün monofilaman sütüre kıyasla daha kısa ameliyat süreleri, daha kısa anastomoz süreleri, daha düşük oranda anastomoz kaçakları ve daha kısa kateterizasyon süreleri sağladığını göstermektedir. Ameliyat sonrasında erken dönem sonuçlar benzer olmakla birlikte 6 . ayda kontinans oranları dikenli sütür lehine gelişim göstermektedir. Daha uzun takip sürelerine ihtiyaç vardır. 
Çıkar Çatışması: Yazarlar çıkar çatışması olmadığını beyan ederler. Çalışma konusuyla doğrudan veya dolaylı olarak ilgili hiçbir

\section{Referanslar}

1. Center MM, Jemal A, Lortet-Tieulent $\mathbf{J}$, et al. International variation in prostate cancer incidence and mortality rates. Eur Urol. 2012;61:1079-92.

2. Jung KW, Park S, Kong HJ, et al. Cancer statistics in Korea: incidence, mortality, survival, and prevalence in 2009. Cancer Res Treat. 2012;44:1124.

3. Holmberg L, Bill-Axelson A, Helgesen F, et al. A randomized trial comparing radical prostatectomy with watchful waiting in early prostate cancer. $\mathrm{N}$ Engl J Med. 2002;347:781-9.

4. Walsh PC. Anatomic radical prostatectomy: evolution of the surgical technique. J Urol. 1998;160(6 Pt 2):2418-24.

5. Ulmer WD, Prasad SM, Kowalczyk KJ, et al. Factors associated with the adoption of minimally invasive radical prostatectomy in the United States. J Urol. 2012;188:775-80.

6. Kim KH, Lim SK, Shin TY, Chung BH, Hong SJ, RhaKH. Biochemical outcomes after robot-assisted radical prostatectomy in patients with follow-up more than 5-years.Asian J Androl. 2013;15:404-8.

7. Menon M, Bhandari M, Gupta N, et al. Biochemical recurrence following robot assisted radical prostatectomy: analysis of 1384 patients with a median 5-year follow-up. Eur Urol. 2010;58:838-46.

8. Sooriakumaran P, Haendler L, Nyberg T, et al. Biochemical recurrence after robotassistedradical prostatectomy in a European single-centrecohort with a minimum follow-up time of 5 years. Eur Urol.2012;62:768-74.

9. Suardi N, Ficarra V, Willemsen P, et al. Long-term biochemical recurrence rates after robot-assisted radical prostatectomy: analysis of asingle-center series of patients with a minimum follow-up of 5 years. Urology. 2012;79:133-8.

10. Branco AW, Kondo W, Henrique A, et al. Laparoscopic running urethrovesical anastomosis with posterior fixation. Urology. 2007; 70:799.

11. Chung SD, Tai HC, Lai MK, et al. Novel inaninate training model for urethrovesical anastomosis in laparoscopic radical prostatectomy. Asian J Surg. 2010; 33:188.

12. Greenberg JA, Clark RM: Advances in suture material for obstetric and gynecologic surgery. Rev Obstet Gynecol 2009; 2: 146.

13. Sammon J, Kim TK, Trinh QD, et al: Anastomosis during robotic assisted radical prostatectomy: randomized controlled trial comparing barbed and standard monofilament suture. Urology 2011; 78: 572.

14. Weld KJ, Ames CD, Hruby G, et al. Evaluation of a novel knotless self-anchoring suture material for urinary tract reconstruction. Urology 2006;67:1133

15. Li H, Liu $\mathrm{C}$, Zhang $\mathrm{H}$ et al. The use of unidirectional barbed suture for urethrovesical anostomosis during taraftan herhangi bir finansal veya finansal olmayan fayda alınmamıştır veya alınmayacaktır. robot assisted radical prostatectomy.: A systematic review and meta analysis of efficacy and safety. Plos One $2015 ; 10$.

16. Zorn KC, Trinh QD, Jeldres $\mathrm{C}$ et al: Prospective randomized trial of barbed polyglyconate suture to facilitate vesico-urethral anastomosis during robotassisted radical prostatectomy: time reduction and cost benefit. BJU Int 2012; 109: 1526.

17. Van Velthoven RF, Ahlering TE, Peltier A, et al. Technique forlaparoscopic running urethrovesical anastomosis:the single knot method. Urology. 2003; 61:699.

18. Warner JP, Gutowski KA. Abdominoplasty with progressive tension closure using a barbed suture technique. Aesthet Surg J 2009;29:221e5.

19. Rashid RM, Sartori M, White LE, Villa MT, Yoo SS, Alam M. Breaking strength of barbed polypropylene sutures: raterblinded, controlled comparison with nonbarbed sutures of various calibers. Arch Dermatol 2007; 143:869e72.

20. Ethicon Inc., Wound Closure Manual; 2005. Available at: http://www.uphs.upenn.edu/surgery/Education/facili ties/measey/Wound_Closure_Manual.pdf. (accessed December 12, 2014).

21. Covidien, V-LocTM Wound closure devices. 2011. Available http://surgical.covidien.com/imageserver.aspx/v-locwound-closuredevices-productoverview.pdf?contentID=39624\&contenttype $=$ appli cation/pdf. (accessed January 5, 2014).

22. Dennis C, Sethu S, Nayak S et al: Suture materials: Current and emerging trends. J Biomed Mater Res A 2016; 104: 1544

23. Haga N, Kurita N,Yanagida $\mathrm{T}$, et al. Effects of barbed suture during robot-assisted radical prostatectomy on postoperative tissue damage and longitudinal changes in lower urinary tract outcome. Surg Endosc (2018) 32:145-153

24. Kaul S, Sammon J, Bhandari A, Peabody J, Rogers CG, Menon M. A novel method of urethrovesical anastomosis during robot-assisted radical prostatectomy using a unidirectional barbed wound closure device: Feasibility study and early outcomes in 51 patients. J Endourol 2010; 24:1789-1793.

25. Williams SB, Alemozaffar M, Lei $Y$, et al: Randomized controlled trial of barbed polyglyconate versus polyglactin suture for robot-assisted laparoscopic prostatectomy anastomosis: technique and outcomes. Eur Urol 2010; 58: 875.

26. Massoud W, Thanigasalam R, El Hajj A, et al. Does the use of a barbed polyglyconate absorbable suture have an impact on urethral anastomosis time, urethral stenosis rates, and cost effectiveness during robot-assisted radical prostatectomy?. Urology. 2013;82(1):90-94.

27. Tewari AK, Srivastava A, Sooriakumaran P, et al. Use of a novel absorbable barbed plastic surgical 
suture enables a "self-cinching" technique of vesicourethral anastomosis during robot-assisted prostatectomy and improves anastomotic times. J Endourol. 2010;24:1645-1650.

28. Polland AR, Graversen JA, Mues AC, Badani KK. Polyglyconate unidirectional barbed suture for posterior reconstruction and anastomosis during robot-assisted prostatectomy: Effect on procedure time, efficacy, and minimum 6-month follow-up. J Endourol 2011;25:1493-1496.
29. Hemal AK, Agarwal MM, Babbar P. Impact of newer unidirectional and bidirectional barbed suture on vesicourethral anastomosis during robot-assisted radical prostatectomy and its comparison with poliglekapron-25 suture: an initial experience. Int Urol Nephrol 2012;44:125

30. Manganiello M, Kenney $\mathrm{P}$, Canes $\mathrm{D}$, et al. Undirectional barbed suture versus standard monofilament for urethrovesical anastomosis during robotic assisted laparoscopic radical prostatectomy. Int Braz J Urol. 2012; 38:89 